\title{
Role of fibrillin-1 genetic mutations and polymorphism in aortic dilatation in patients undergoing intracardiac repair of tetralogy of Fallot
}

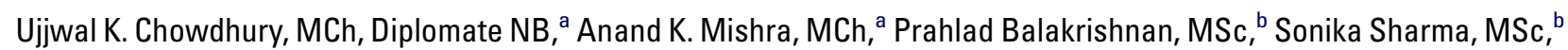
Madhulika Kabra, MD, ${ }^{\mathrm{b}}$ Ruma Ray, MD, MRC (Path), ${ }^{\mathrm{b}}$ Mani Kalaivani, MSc (Biostatistics), ${ }^{\mathrm{c}}$ Ruchika Gupta, MD (Path), ${ }^{\mathrm{b}}$ Raghu M. Govindappa, MS, and Ganapathy K. Subramaniam, $\mathrm{MCh}^{\mathrm{a}}$

丹 Supplemental material is available online.
From the Departments of Cardiothoracic Surgery, ${ }^{\mathrm{a}}$ Pediatrics (Genetics), ${ }^{\mathrm{b}}$ and Biostatistics, ${ }^{\mathrm{c}}$ All India Institute of Medical Sciences, New Delhi, India.

Received for publication July 4, 2007; revisions received Nov 13, 2007; accepted for publication Dec 7, 2007.

Address for reprints: Ujjwal K. Chowdhury, $\mathrm{MCh}$, Diplomate NB, Department of Cardiothoracic and Vascular Surgery, All India Institute of Medical Sciences, New Delhi-110029, India (E-mail: ujjwalchow@ rediffmail.com; ujjwalchowdhury@gmail. com).

J Thorac Cardiovasc Surg 2008;136:757-66 $0022-5223 / \$ 34.00$

Copyright (C) 2008 by The American Association for Thoracic Surgery

doi:10.1016/j.jtcvs.2007.12.044
Objective: The purposes of this study were to identify the occurrence of fibrillin-1 gene polymorphisms or mutations in exons 24 to 28 and to identify the relationship between "DNA sequence variants" and aortic dilatation in the presence of abnormal aortic histopathology and other variables in patients undergoing intracardiac repair of tetralogy of Fallot.

Methods: Operatively excised full-thickness aortic wall tissue and 5 to 10 -mL venous blood samples from 74 consecutive patients undergoing intracardiac repair of tetralogy of Fallot were studied. Histopathologic evaluation was done by light microscopy. Polymerase chain reaction amplification of fibrillin-1 gene was carried out for 5 exons (24-28), and amplified products were subjected to single-strand conformation polymorphism analysis to identify sequence alterations, if any. Logistic regression analysis was done to identify the relationship between patients with and without "exonic DNA variants" with other risk factors causing aortic dilatation.

Results: Sixteen aortic tissue specimens (21.6\%) were indicated as histologically normal and used as controls. Of 51 patients with dilated aorta, $48(94.1 \%)$ exhibited histologic abnormalities. The incidences of significant lamellar loss, abnormal histopathology, and fibrillin-1 "DNA sequence variants" in tetralogy of Fallot with dilated aorta were $78.4 \%, 96.1 \%$, and $50.9 \%$, respectively. The risk of aortic dilatation was 8.83 (1.94-13.99) times greater in patients with histologically abnormal aorta and 8.11 (1.93-34.04) times greater in patients with fibrillin-1 "exonic DNA variants."

Conclusion: Our findings indicate the existence of "exonic DNA variants" involving the fibrillin-1 gene in 1 or more exons (exon 24-28). The "DNA sequence variants" are more pronounced in patients with tetralogy of Fallot and dilated aorta in the presence of abnormal aortic histopathology.

A lthough aortic root dilatation has been reported in patients with tetralogy of Fallot (TOF) even after reparative surgery, its pathophysiology remains elusive. ${ }^{1-4}$ It is hypothesized that medial abnormality coupled with increased aortic blood flow might be the cause for aortic root dilatation in untreated patients. ${ }^{4-9}$ In our earlier publication, we demonstrated the occurrence of marked histopatholologic changes, ranging from loss and fragmentation of elastic lamellae, increased accumulation of ground substance, medionecrosis, and fibrosis in the aortic media of ascending aorta of patients undergoing intercardiac repair of TOF. These changes were present in infancy and more pronounced in older patients subjected to longstanding cyanosis and volume overload. ${ }^{10}$

These histopathologic changes resemble those observed in both bicuspid aortic valve disease and Marfan syndrome. ${ }^{11,12}$ The genetic basis of Marfan disease has recently been classified, with mutations of the fibrillin-1 genes being responsible for 


$$
\begin{aligned}
& \text { Abbreviations and Acronyms } \\
& \begin{aligned}
\text { CI } & =\text { confidence interval } \\
\text { DORV } & =\text { double outlet right ventricle } \\
\text { MAPCA } & =\text { major aortopulmonary collateral artery } \\
\text { OR } & =\text { odds ratio } \\
\text { PCR } & =\text { polymerase chain reaction } \\
\text { ROC } & =\text { receiver operating characteristic } \\
\text { SSCP } & =\text { single-strand conformation polymorphism } \\
\text { TOF } & =\text { tetralogy of Fallot }
\end{aligned}
\end{aligned}
$$

most cases. Fibrillin-1 gene is preferentially found in elastic tissue (eg, tunica media of the aorta), and defects in its expression are also implicated in other fibrinopathies. ${ }^{13-16}$ The fibrillin-1 gene mutations in Marfan syndrome are normally clustered in the region of exons 24 to $28 .^{13-16}$

Because of the similarity of histopathologic changes of the aortic media of patients with TOF, bicuspid aortic valvular disease, and other fibrinopathies, and the implication of fibrillin-1 gene in Marfan syndrome, we hypothesized that fibrillin1 gene polymorphisms and mutations may have a biologically plausible role in the development of dilated aortas in patients with TOF.,6-16 We focused our search for fibrillin-1 gene polymorphisms and mutations on exons 24 to 28 on the basis that most of the fibrillin-1 gene mutations in Marfan syndrome are normally clustered to these 5 exons.

With this background, we conducted this study to i) identify the prevalence of fibrillin-1 gene polymorphisms or mutations, if any, in exons 24 to 28 (the region of clustering of mutations in Marfan syndrome) among patients with TOF undergoing intracardiac repair; ii) elucidate the histopathology of the aortic wall in patients with TOF and identify the histopathologic characteristics and other risk factors that may predispose patients to a higher risk of aortic dilatation seen in these patients; and iii) identify the relationship among gene polymorphisms, mutations, and aortic dilatation in the presence of abnormal aortic histopathology and other variables.

\section{Patients and Methods}

\section{Patient Selection Criteria}

The study was approved by the institutional review board of the All India Institute of Medical Sciences, New Delhi, India, and patients with TOF were enrolled according to the guidelines established by the institutional ethics committee for human subject research.

In our earlier publication, we addressed the histopathologic findings of the aortic wall of the same patient population undergoing intracardiac repair of TOF and analyzed the risk factors related to abnormal histopathology and aortic dilatation. ${ }^{10}$ To test our postulates, we embarked on a program of fibrillin-1 gene mutational/polymorphism analysis on patients undergoing intracardiac repair of TOF between January of 2004 and June of 2006. All patients with TOF, regardless of age, sex, or race, were approached to participate in the protocol. The patients were entered in the study protocol after informed consent for genetic investigations and aortic wall biopsy had been obtained from their parents or guardians.

In this study, we have attempted to analyze specifically the relationship of genetic defect involving the fibrillin-1 gene with aortic dilatation in the presence of abnormal aortic histopathology and other candidate variables. The postoperative outcome of these patients and the findings of risk factor analyses are not repeated here.

All operations in this study population were performed by a single surgeon (U.K.C.), maintaining uniformity in the study protocol. Thus, of 108 consecutive patients undergoing intracardiac repair of TOF, 89 consented to genetic investigations and were enrolled prospectively into the study. All subjects were tested for $22 \mathrm{q} 11$ deletion by fluorescence in situ hybridization. Patients with a 22q11 deletion $(\mathrm{n}=9)$ and trisomy $21(\mathrm{n}=6)$ were excluded from the present study. ${ }^{17,18}$

Venous blood samples from these 74 patients ( 52 male) were obtained for genetic studies, and specimens of the aortic wall from these 74 patients were also subjected to histopathologic analysis.

\section{Patient Characteristics}

Age at correction was 6 months to 45 years (mean, 112.6 \pm 104.52 ; median, 80 months), with $28.4 \%$ of patients $(n=21)$ aged less than 4 years and $27 \%$ of patients $(n=20)$ aged more than 12 years. Cardiac catheterization and angiocardiography were performed in all patients to confirm the diagnosis, define coronary artery anatomy, and identify major aortopulmonary collateral arteries (MAPCAs).

Aortic diameter measured echocardiographically in our study showed significant dilatation in $68.9 \%$ of patients $(n=51)$ with TOF. Aortic dilatation was defined as the ratio of observed to expected aortic root diameter index to body surface area and age greater than 1.5. ${ }^{19}$ The demographic and clinical characteristics of patients with normal $(n=23)$ and dilated aorta $(n=51)$ in this study population are shown in Tables E1 and E2. Of 51 patients with aortic dilatation, $31(60.7 \%)$ were aged more than 96 months, 44 $(86.2 \%)$ were male, $37(72.5 \%)$ had an $\mathrm{SAO}_{2}$ less than $80 \%$ and hematocrit greater than $45 \%, 40(78.4 \%)$ had aortic override greater than 50\%, 12 (23.5\%) had aortic regurgitation, 27 (52.9\%) demonstrated the presence of MAPCAs, $19(37.2 \%)$ had right aortic arch, $20(39.2 \%)$ had a TOF diagnosis with pulmonary stenosis, and 31 $(60.7 \%)$ had a double outlet right ventricle (DORV) or TOF with pulmonary atresia diagnosis (Table E2).

Our study illustrates that the clinical characteristics of the patients with normal and dilated aortas, including age and other variables, are not similar. Of 51 patients with aortic dilatation, 49 (96\%) exhibited histologic abnormalities and 26 (50.9\%) exhibited fibrillin-I "DNA sequence variants" in 1 or more chromosomes (exons 25-28). To identify the relationship between fibrillin-1 genetic polymorphisms and mutations and aortic dilatation, a multivariate logistic regression model was used with adjustment for all the variables, including age and abnormal aortic histopathology (Tables E1-E5).

Standard cardiopulmonary bypass and myocardial protection techniques were used in all patients. Intracardiac repair was performed with a transatrial, transpulmonary approach in 58 patients (78.4\%) and a trans-right atrial approach in 16 patients $(21.6 \%)$.

There were 3 perioperative deaths $(4 \%)$ caused by massive pulmonary bleeding $(\mathrm{n}=2)$ and low cardiac output syndrome and multiorgan failure $(n=1)$. There were no late deaths. The details of the postoperative course and follow-up of these patients have been addressed in our earlier publication. ${ }^{10}$ 


\section{Collection of Samples for Genetic Studies}

Approximately 5 to $10 \mathrm{~mL}$ of venous blood samples were obtained in ethylenediamine tetraacetic acid tubes for genetic studies. Genomic DNA was extracted using conventional phenol-chloroform method.

\section{Collection and Preparation of Tissues}

The aortic tissues studied were operatively excised from the aortic cannulation site. A button of full-thickness aortic wall tissue $(\sim 2-$ $3 \mathrm{~mm}$ in width) was excised from within the aortic pursestring suture on a side-biting aortic clamp as atraumatically as possible. Excised full-thickness aortic wall tissue during intracardiac repair was subjected to histopathologic evaluation by light microscopy.

\section{Light Microscopy Evaluation}

Each biopsy specimen was fixed in $10 \%$ buffered formalin solution at room temperature and embedded in paraffin block, and thin sections of 4 to $5 \mu \mathrm{m}$ were taken. The slides were then stained with hematoxylin-eosin. Special stains, such as Masson's trichrome, elastic Verhoeff Van Gieson, and Alcian blue Periodic Acid Schiff, were used as and when indicated. The sections were examined with a research light microscope (Nikon Optiphot, Nikon Corporation, Tokyo, Japan, magnification $40 \times, 100 \times$, or $200 \times$ ).

The histopathology slides were simultaneously evaluated by 2 independent observers, and there was no interobserver disagreement or interpretation of the presence and absence of disease. The histologic evaluation of the aortic media included 6 variables: 1) lamellar count, 2) loss or fragmentation of elastic lamellae, 3) increased amount of ground substance, 4) medionecrosis, 5) smooth muscle disarray (changes in smooth muscle orientation), and 6) fibrosis. The lesions were graded 1 to 3 according to the criteria adapted from de Sa and associates ${ }^{11}$ and Schlatmann and Becker ${ }^{20}$ (Table E6).

The grades were determined on the basis of the worst area observed in each specimen. The number of elastic lamellae was counted at the thickest and thinnest areas in the media, and the mean of these numbers was calculated. The longer elastic lamellae parallel to the lumen were included while counting.

\section{Molecular Genetic Studies}

Polymerase chain reaction amplification and single-strand conformation polymorphism analysis. Polymerase chain reaction (PCR) was carried out with 100 ng of genomic DNA. The coding region of fibrillin-1 gene, including exon-intron boundaries, was amplified for 5 exons (24-28) using previously published primers (Table E7). ${ }^{21}$

To identify the known and unknown "DNA sequence variants," the amplified products were subjected to single-strand conformation polymorphism (SSCP) analysis for 5 exons of fibrillin-1 gene on 74 patients undergoing intracardiac repair of TOF and on 52 normal patients from the general population using the modified method (Table E8). ${ }^{21-23}$

Among 74 patients undergoing intracardiac repair of TOF, 16 $(21.6 \%)$ did not exhibit any histologic abnormalities and were used as the control group. These 16 control subjects contributed 32 reference alleles to the analysis. To determine the prevalence of fibrillin-1 "DNA sequence variants" in the general population, we performed SSCP analysis on 52 subjects from the normal population, thus contributing 104 reference alleles for data analysis.

All the samples exhibiting shifts were sequenced along with 16 randomly selected samples with no shifts using a commercially available automatic sequencer (ABI 3700, Macrogen, Seoul, Korea). The sequencing results were compared with the original data using NCBI BLAST (Gen Bank Accession No. AC022467 and AC 084757).

\section{Definitions}

Aortic root dilatation. Age, height, body weight, and sex are known to be the determinants of aortic root dimensions in the normal heart. ${ }^{24,25}$ Therefore, we used the standard normogram for aortic root size at the sinotubular junction adopted from Roman and associates, ${ }^{25}$ indexed to body surface area and age. ${ }^{19,24}$ Aortic root dilatation was defined as the ratio of observed to expected aortic root diameter greater than $1.5 .^{24,25}$

Apoptosis. Apoptosis is defined as a form of programmed cell death and has been recognized as a central feature of fundamental biological processes, including embryonic morphogenesis, remodeling of mature tissues, and cell replacement in certain adult tissues (eg, the thymus). In contrast with necrosis, apoptosis occurs in isolated cells without any accompanying cellular reaction. ${ }^{26}$

Elastic fragmentation. Elastic fragmentation is defined as focal fragmentation of elastic lamellae in the aortic media. Three grades were recognized: grade 1: fewer than 5 foci of elastic lamellae, loss or fragmentation in 1 microscopic field, each focus comprising 2 to 4 neighboring elastic lamellae; grade 2: 5 to 9 foci of elastic lamellae fragmentation in 1 microscopic field; grade 3: presence of 10 or more foci of elastic fragmentation in 1 microscopic field (Table E6).

Accumulation of ground substance. The ground substance is a hydrated gel composed of glycosaminoglycans, proteoglycans, and adhesive glycoproteins in which elastic fibers and collagen are embedded. ${ }^{11,20}$ Accumulation of ground substance was characterized by a noninflammatory loss of smooth muscle cells in the presence of intact elastic lamellae and fragmented elastic fibers. There was mucoid degeneration with no identifiable cystic wall.

In grade 1, there was mild fragmentation of elastic fibers with a mild increase in ground substance and little or no change in smooth muscle. In grade 2 , there was widespread elastic fiber fragmentation, further increase in ground substance, and widespread loss of smooth muscle. In grade 3, there were large areas of complete loss of elastic fibers and smooth muscle, and large areas of ground substance accumulation (Table E6). ${ }^{11,20}$

Medionecrosis. Medionecrosis is defined as a focal loss of smooth muscle nuclei in the media. Three grades were recognized (Table E6).

Smooth muscle disarray (changes in smooth muscle orientation). Three grades were recognized: grade 1: smooth muscle disarray involving less than one third of the thickness of the media; grade 2: smooth muscle disarray involving one third to one half of the thickness of the media; grade 3: large area of smooth muscle disarray involving more than one half of media thickness, associated with elastic fragmentation (Table E6).

Fibrosis. Fibrosis is defined as an increase in interstitial collagen. Three grades were recognized (Table E6).

DNA sequence variants. The term refers to any changes in the DNA sequence observed in cases (in this study, patients with TOF and enlarged aortas) and control subjects.

Genetic polymorphisms. The term refers to the simultaneous occurrence in the population of genomes showing allelic variations. Any site at which multiple alleles exist as stable components of 
the population is by definition polymorphic. An allele is usually defined as polymorphic if it is present at a frequency of more than $1 \%$ in the population. ${ }^{23}$

Mutations. Mutations have been defined as DNA sequence variants that were seen in cases (in this case, patients with TOF and enlarged aortas) but not among controls. The term "mutation" indeed has more functional implications or at least is not present in the general population. Point mutations are changes involving single base pairs. Frameshift mutations arise by deletions or insertions that are not a multiple of 3 base pairs; they change the frame in which triplets are translated into protein. ${ }^{23}$

Polymerase chain reaction. PCR describes a technique in which cycles of denaturation, annealing with primer, and extension with DNA polymerase are used to amplify the number of copies of a target DNA sequence by more than $10^{6}$ times. ${ }^{21-23}$

Shift on single-strand conformation polymorphism. In this study, genetic shift means the actual shift or mobility change of the PCR product observed during SSCP analysis. A truly genetic shift has more population-based implications and was not evaluated in this study. ${ }^{23}$

Single-strand conformation polymorphism analysis. This is the simplest, easiest, and most commonly used method for screening small fragments (200-400 base pairs) of DNA. Because SSCP allows one to initially screen small fragments of DNA, one can rapidly screen a larger number of samples for potential sequence alterations. Identification of a few samples with base pair changes thus allows one to concentrate sequencing efforts on the most important specimens.

SSCP analysis basically involves separation of PCR strands on a nondenaturing polyacrylamide gel. Double-stranded DNA is denatured, and single-stranded DNA is seen on the nondenaturing polyacrylamide gel. As the strands migrate through the gel, they assume their normal conformation and migrate at different rates producing 2 distinct bands. Alterations in base sequence forces the individual strands to assume a somewhat different conformation, and this results in a diagnostic "band shift" or "change of mobility" of 1 or both fragments. These samples are sequenced to identify the changes in base sequence in the DNA. Fragments can be visualized by either end labeling the primers with $\mathrm{p} 32$ or using sensitive dyes in a radioactive free "cold SSCP.",21-23

\section{Statistical Methods and Analysis}

Statistical analysis was performed with Intercooled STATA 9.0 Software (College Station, Tex). Interval-related data were expressed as mean \pm standard deviation, and categoric variables were expressed as percentages. The difference in proportions was tested using the chi-square test.

The receiver operating characteristic (ROC) analysis was performed to determine the cutoff value of the lamellar count, which will predictably separate normal from the abnormal considering aortic dilatation as the outcome and taking histopathology as the gold standard. To quantify the predictive accuracy of the lamellar count, the area under the ROC curve was analyzed (Figure 1).

Aortic tissue specimens without histologic abnormalities were defined as normal and used as normal controls. The simple logistic regression followed by forward stepwise multiple logistic regression analysis was used to identify the independent risk factors associated with the diseased pathology and aortic dilatation. Subsequently, stepwise forward logistic regression analysis was performed to identify the relationship, if any, between patients with and without "ex-

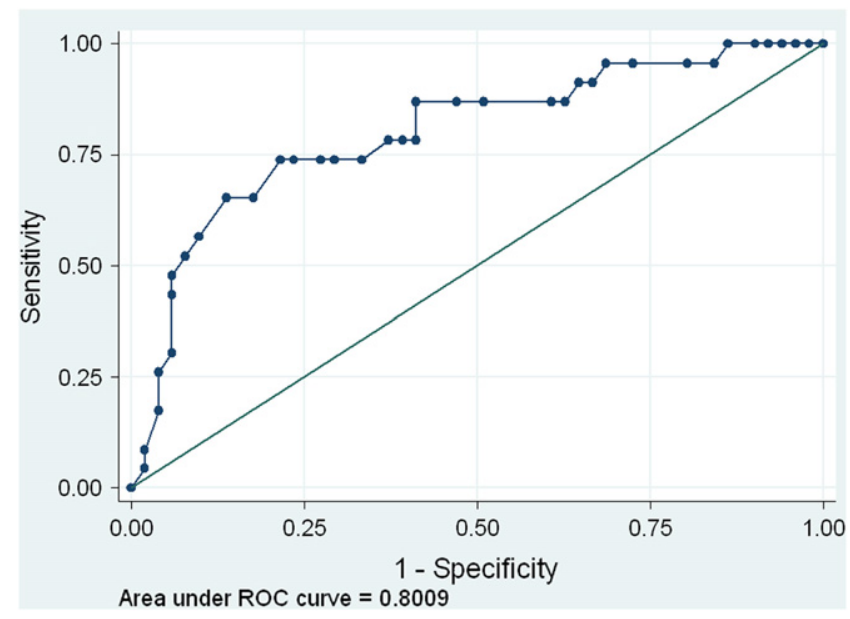

Figure 1. ROC of the study group to compare the tradeoffs between the true-positive rate and the false-positive rate of low lamellar count. A lamellar count of 55 as the optimal cutoff point for aortic dilatation in patients undergoing intracardiac repair with a sensitivity of $\mathbf{7 8 . 4 \%}$ and specificity of $\mathbf{7 3 . 9} \%$.

onic DNA sequence variants" with other risk factors causing aortic dilatation, including abnormal histopathology.

The non-encoding regions of the genome (intronic) variants were considered as biologically insignificant in causing the disease and were excluded from data analysis. Therefore, DNA sequence variants from encoding regions (exons only) were considered for statistical analysis. The results were expressed as odds ratio (OR) and 95\% confidence interval (CI) for each independent variable.

\section{Results}

\section{Histopathology and Risk Factor Analysis}

Sixteen aortic tissue specimens $(21.6 \%)$ were found to be histologically normal and used as controls. These specimens exhibited layers of longitudinally arranged elastic lamellae interspersed with smooth muscle cells and collagen fibrils in a mucopolysaccharide ground substance.

Elastic fragmentation, increased ground substance, medionecrosis, smooth muscle disarray, and fibrosis were present in 58 (78.4\%), 43 (58.1\%), 37 (36.5\%), 27 (36.5\%), and 45 $(60.8 \%)$ specimens, respectively (Table E3). Because both the pathologists agreed in saying 58 abnormal histopathology specimens as abnormal and 16 normal aortic tissue sections as normal, the Kappa value is 1.00. The risk factors for these histopathologic changes in this study population have been enumerated in detail in our previous publication and are not repeated here. ${ }^{10}$

\section{Relationship Between Aortic Root Dilatation and Other Candidate Variables Including "Exonic DNA Sequence Variants" and Histologic Abnormalities} Aortic diameter measured echocardiographically in our study showed significant dilatation in $68.9 \%$ of patients $(n=51)$ 
with TOF. To assess the association between genetic shift and aortic root dilatation in TOF, aorta with and without histologic abnormalities, patients with and without fibrillin1 "exonic DNA sequence variants," and other candidate variables were taken into consideration (Table E3).

Aortic tissue specimens without histologic abnormalities $(n=16)$ were defined as normal and used as the control group. Of 51 patients with aortic dilatation, 49 (96\%) exhibited histologic abnormalities and 26 (51\%) exhibited "exonic DNA sequence variations" involving the fibrillin-1 gene in 1 or more chromosomes (exons 25-28). Some 27 of 28 patients $(96.5 \%)$ with genetic abnormalities exhibited abnormal histopathology of the aortic media (Tables E2 and E3).

It is noteworthy that $96.4 \%$ of patients with elastic fragmentation $(P=.003), 78.6 \%$ of patients with increased ground substance $(P=.005), 67.8 \%$ of patients with medionecrosis $(P=.017), 53.6 \%$ of patients with muscle disarray $(P=.017)$, and $78.6 \%$ of patients with fibrosis $(P=.015)$ exhibited "exonic DNA sequence variations" involving the fibrillin-1 gene in 1 or more chromosomes (exons 27 and 28) (Table E3).

Of 28 patients with fibrillin-1 "exonic DNA variants," 19 (67.9\%) were aged more than 96 months, 24 (85.7\%) were male, $22(78.6 \%)$ had systemic arterial desaturation $(<80 \%), 22(78.6 \%)$ had a hematocrit level greater than $45 \%, 24(85.7 \%)$ had aortic override greater than 50\%, 19 (67.8\%) had MAPCAs, 13 (46.4\%) had right aortic arch, and $21(75 \%)$ had low lamellar count $(<55)$ (Table E3).

The presence of elastic fragmentation, increased ground substance, medionecrosis, muscle disarray, fibrosis, age more than 96 months, male sex, systemic arterial desaturation $(<80 \%)$, hematocrit level greater than $45 \%$, aortic override greater than $50 \%$, presence of aortic regurgitation, MAPCAs, higher right ventricular end-diastolic pressure $(>12 \mathrm{~mm} \mathrm{Hg})$, right aortic arch, DORV, TOF with pulmonary atresia, and previous systemic-to-pulmonary-artery-shunting procedures were independent risk factors for aortic root dilatation according to bivariate analysis (Table E2).

Logistic regression analysis identified histopathologically abnormal aorta, elastic fragmentation, increased ground substance, male sex, degree of aortic override greater than $50 \%$, and DORV as the predictors for aortic dilatation in this study (Table E4). The risk of aortic dilatation was 8.83 times greater (95\% CI, 1.94-39.99) in patients with histopathologically abnormal aorta and 8.11 times (95\% CI, 1.93-34.04) greater in patients with "exonic DNA variants" involving the fibrillin-1 gene (Table E4).

\section{Logistic Regression Analyses of the Association Between Patients with Fibrillin-1 Genetic Abnormalities and Aortic Dilatation in the Study Population $(\mathbf{n}=\mathbf{7 4})$}

It is noteworthy that in logistic regression analysis, the association between "exonic DNA sequence variants" and aortic di- latation showed a significant relationship with an OR of 10.92 (95\% CI, 2.31-51.49). The OR remained significant while adjusting for age (6.87 [95\% CI, 1.33-35.49; $P=.02])$ and for age, increased ground substance, MAPCAs, abnormal lamellar count (9.85 [95\% CI, 1.03-94.22; $P=.04]$ ).

The adjustment for differences in age, medionecrosis, MAPCAs, abnormal lamellar count, and for differences in age, muscle disarray, MAPCAs, and abnormal lamellar count resulted in a moderate weakening of the OR to $6.49(95 \% \mathrm{CI}$, $0.99-42.26 ; P=.05)$ and $6.38(95 \% \mathrm{CI}, 0.98-41.50 ; P=$ $.05)$, respectively.

The relationship between DNA sequence variation and aortic dilatation became even weaker when adjusted for age and abnormal histopathology to 4.59 (95\% CI, 0.7727.53). The adjustment for age, elastic fragmentation, presence of MAPCAs, abnormal lamellar count, and for age, fibrosis, presence of MAPCAs, and abnormal lamellar count increased the OR to 3.93 (95\% CI, 0.53-28.97) and 4.96 (95\% CI, 0.58-42.93), respectively, although both were nonsignificant (Table E5).

\section{Relationship Between Lamellar Count and Aortic Dilatation in Tetralogy of Fallot}

Analysis of the ROC curve. The mean lamellar count in this cohort with and without histologic abnormalities (control group) was $37.3 \pm 8.7$ (range 15-51, median 39.5) and 63.5 \pm 6.3 (range 55-75, median 61.5), respectively (Figure 1). By pairwise comparisons, the differences in lamellar count of both groups of patients were statistically significant $(P<.0001)$.

A mean lamellar count of $37.3( \pm 8.7$, range $15-52)$ was always associated with a histologically abnormal aorta and aortic dilatation $(\mathrm{OR}=0.80 \quad[95 \%$ CI, 0.68-0.91]; $P<.0001)$.

With a lamellar count of 55 as the optimal cutoff point for abnormal aortic histopathology in patients undergoing intracardiac repair of TOF, the sensitivity was $78.4 \%$ and the specificity was $73.9 \%$. The predictive accuracy of a positive or negative result was $86.9 \%$ and $60.7 \%$, respectively. Area analysis under the ROC curve indicated that $80.1 \%$ (standard error \pm 0.06 ; $95 \%$ CI, 0.68-0.92) of the time, the values of lamellar count were lower for patients with aortic dilatation in patients undergoing intracardiac repair of TOF compared with abnormal histopathology, which is highly significant $(P<.001)$ (Figure 1)

\section{Genetic Mutation Analysis}

We identified the following changes on PCR amplification and SSCP analysis:

Control samples (52 healthy subjects; 104 reference alleles) from the general population

- There were no shifts in the SSCP gels for exons 24, 25, 26, and 27 on any control samples. 
- In exon 28, 3 control samples had S-type of shift and 3 control samples had S1 type of shift. All shifts were observed on the non-encoding regions of the genome (intronic) variants and thus were biologically insignificant.

Samples from patients undergoing intracardiac repair of TOF:

- There were no shifts in the SSCP gels for exon 24 (Figure 2, A).

- In exons 25 and 26, there were 5 shifts. All shifts were observed in the same patients. On sequencing of exons 25 and 26, we detected 6 base pair deletions ([del TCTTTA] [3341 + 55]) in the intron area of 25 and there were no changes in the exons (Figure 2, $B$ and $C$ ).

- In exon 27, 5 similar kind of shifts were observed in 5 patients. Sequencing showed a substitution change (c. $3575 \mathrm{C}<\mathrm{G}$ ) in the exonic region of exon 27 of the fibrillin-1 gene leading to a change in amino acid sequence (p.P1148A) (Figure 2,D). This was reported earlier as mutation and later confirmed as polymorphism.

- Exon 28 exhibited a number of shifts in SSCP analysis on 28 patients. Sequencing revealed 2 different deletions on 2 patients in the intron of exon 28 . The first deletion (del ATTTTT) of 6 base pairs was far $(>50$ base pairs) from the exon 28 . The second deletion of 5 base pairs (del TTATG) was toward the acceptor site (9 base pairs) (Figure 2, E).

- The rest of the samples did not show any sequence change.

\section{Discussion}

To our knowledge, there are no studies in the English language literature addressing specifically the relationship of "DNA sequence variants" involving the fibrillin-1 gene with aortic dilatation in the presence of intrinsic aortopathy involving the ascending aorta in TOF.

We studied 5 exons of the fibrillin- 1 gene in patients with TOF and aortic root dilatation. These 5 exons (24-28) were chosen because most mutations in Marfan syndrome have been reported in these cases. ${ }^{12-16}$

The first important finding of this study is the occurrence of aortic dilatation in $69 \%$ of patients before undergoing intracardiac repair of TOF. The second important finding of this study is the occurrence of significant lamellar loss (lamellar count <55), abnormal histopathology, and fibrillin-1 "DNA sequence variants" in 78.4\% (40/51), 96\% (49.51), and $50.9 \%(26 / 51)$ of patients, respectively, with aortic dilatation undergoing intracardiac repair of TOF. The third important finding of this study is the significant loss of lamellar counts and the prevalence of intrinsic abnormal histopathology of the aortic wall, including elastic fragmentation and disruption in patients as early as 6 months of age.

\section{Aortic Dilatation, Lamellar Loss, Abnormal Histopathology, and Fibrillin-1 "DNA Sequence Variants" in Tetralogy of Fallot}

Analysis of the published literature documents up to a $15 \%$ incidence of aortic root dilatation in patients undergoing intracardiac repair of TOF. ${ }^{1-4}$ The aortic root dilatation is at times progressive, necessitating aortic valve or aortic root surgery and has been reported to occur in unoperated and operated patients late after repair. ${ }^{1-9}$ In the Mayo Clinic series, the largest aortic root measured was $85 \mathrm{~mm}$ in diameter without dissection. ${ }^{2}$ The literature documents 2 isolated reports of aortic dissection with aortic root diameters of $6.45 \mathrm{~cm}^{27}$ and $6.1 \mathrm{~cm}^{28}$

In this study, $69 \%$ of patients $(n=51)$ undergoing intracardiac repair of TOF demonstrated aortic root dilatation before surgical repair. The degree of aortic regurgitation in this study population was mild and of no clinical consequence.

Six variables have been found to potentially influence aortic dilatation: 1) abnormal morphogenesis resulting in unequal division of the fetal truncus, favoring aorta; 2) migration of the neural crest cells into the cardiac outflow tract, influencing medial degeneration; 3) volume overload implicit in the biventricular aorta; 4) aortic regurgitation that creates volume overload and introduces pulsatile flow facilitating dilatation; 5) intrinsic medial degenerative changes; and 6) increased or premature destruction of extracellular matrix proteins (ie, elastic fibers). ${ }^{1-10,29,30}$ In operated patients with TOF, the cause of aortic root dilatation is thought to be predominantly secondary to chronic hemodynamic stress from volume overload of the aorta.

It is noteworthy that of these 51 patients with dilated aorta, $49(96 \%)$ exhibited histologic abnormalities and $2(4 \%)$ were histologically normal. It is hypothesized that this intrinsic abnormality may be programmed cell death or an expression of a thus far unrecognized genetic defect involving the cellular function in the aortic media of patients with TOF. ${ }^{4,6-8,26}$

Logistic regression analysis of this study, including our previous publication accounting for the effects of other variables, demonstrated a relationship between aortic root dilatation and male sex, aortic override greater than 50\%, presence of DORV, elastic fragmentation, increased ground substance, and presence of fibrillin-1 "DNA sequence variations." 10 The risk of aortic dilatation was 8.83 times $(95 \% \mathrm{CI}$, $1.94-39.99, P=.005)$ greater in patients with histologically abnormal aorta and 8.11 times (95\% CI, 1.93-34.04, $P=$ $.004)$ greater in patients with exonic fibrillin-1 DNA variants (Tables E2, E4, and E5).

There was a statistically significant interrelationship between lamellar loss and appearance of abnormal histopathology. A mean lamellar count of 37.3 was always associated with a histologically abnormal aorta and aortic dilatation (OR 0.80; 95\% CI, 0.68-0.91; $P<.001$ ). A lamellar count of less than 55 was associated with a sensitivity of $78.4 \%$ and a specificity of $73.9 \%$. The predictive accuracy of 

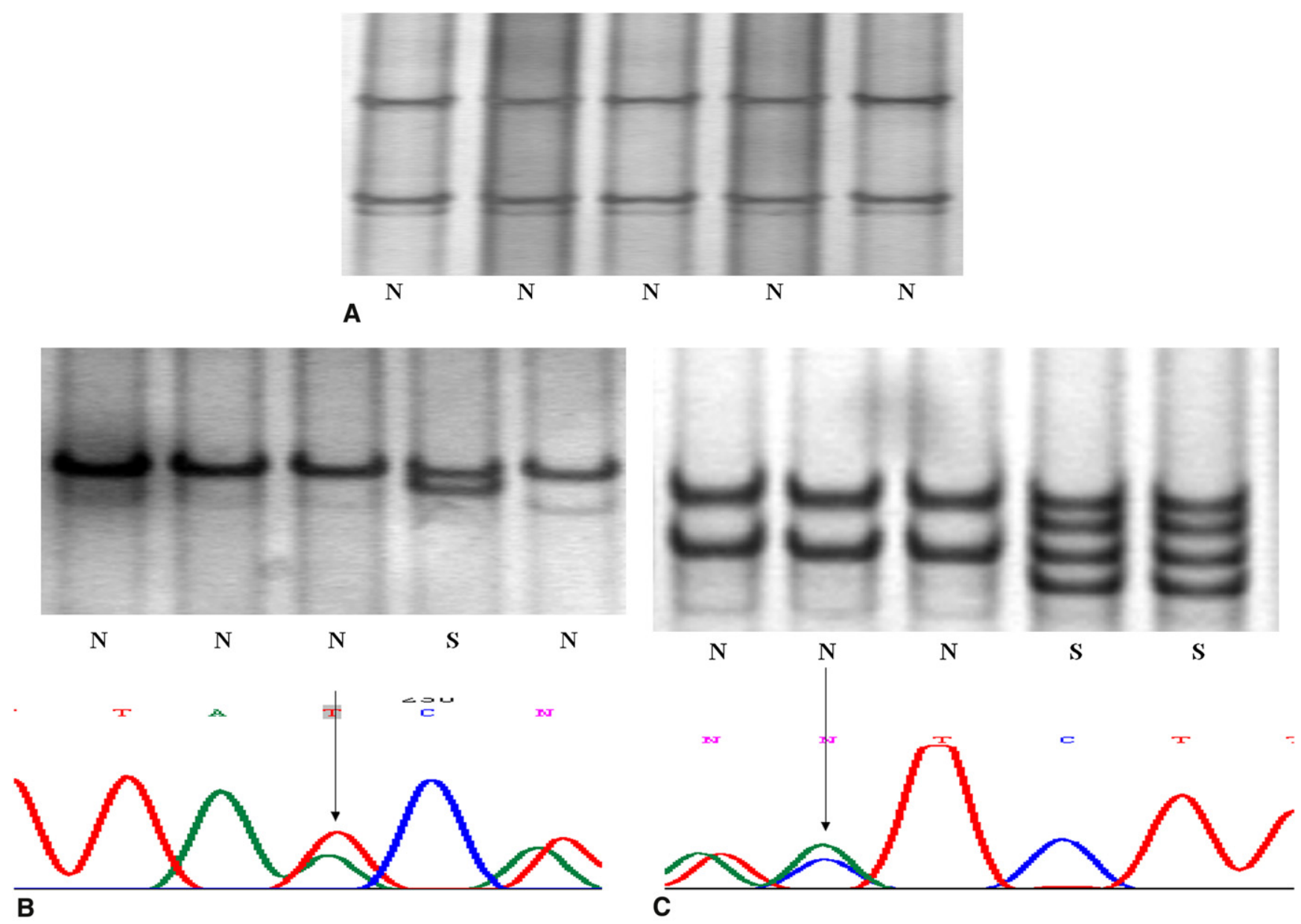

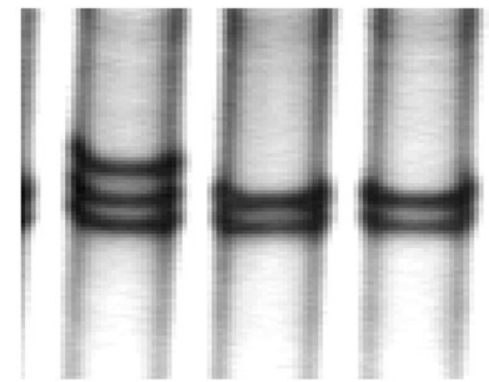

S

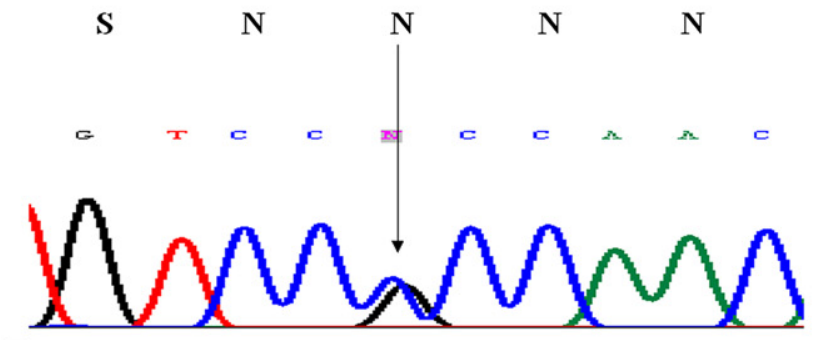

D
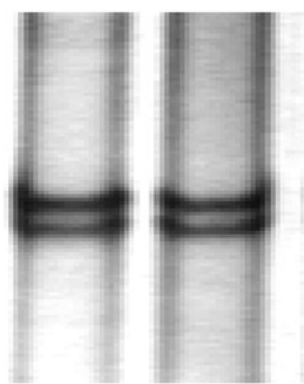

Type S

Type S1
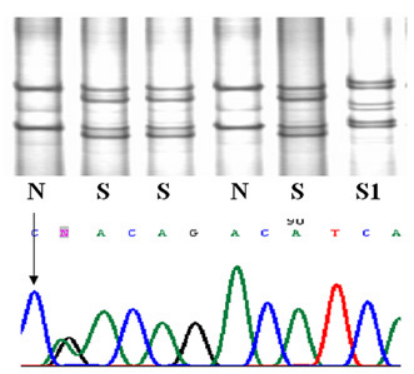

del TTATG

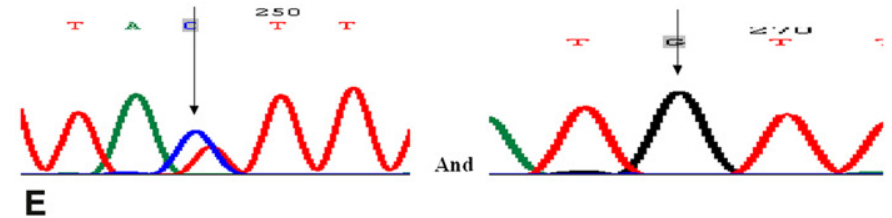

Figure 2. A, SSCP gel picture of exon 24. B, SSCP gel picture of exon 25. C, SSCP gel picture of exon 26. D, SSCP gel picture of exon 27. E, SSCP gel picture of exon 28. 
a positive or negative result was $86.9 \%$ and $60.7 \%$, respectively. Area analysis under the ROC curve indicated that $80.1 \%$ (standard error \pm 0.06 ) of the time the value of lamellar count was lower for the abnormal histopathology group compared with the normal histopathology group (Table E3, Figure 1).

A total of 21 of 28 patients (75\%) with fibrillin-1 "DNA sequence variants" had a lamellar count less than 55 (range, 15-55). These genetic abnormalities may influence the appearance of histopathologic changes in the aortic wall of patients with TOF as mentioned above. These histologic abnormalities possibly reduce the cohesive and tensile strength of the media and suggest an important causative mechanism for aortic root dilatation.

\section{Relationship Between Patients With and Without Fibrillin-1 Exonic DNA Sequence Variants and Tetralogy of Fallot}

Underlying this tendency to aortic root dilatation are histopathologic changes in the aortic media of the dilated aortic root that resemble those observed in both bicuspid aortic valve disease and Marfan syndrome. ${ }^{11,12}$ The genetic basis of Marfan syndrome, ectopia lentis, and associated connective tissue disorders have recently been classified, with mutations of the fibrillin-1 genes being responsible for most cases. ${ }^{13-16}$

Fibrillin is a 350-kd glycoprotein that is the major component of the 12-mm extracellular microfibrils that act as a network for elastin deposition and is a constituent of the elastic fiber. The fibrillin-1 gene is a component of microfibrils associated with elastic fibers. These microfibrils form a scaffold for deposition and aggregation of elastin, and the defect in their synthesis leads to structural weakness of the vascular walls. It is found preferentially in elastic tissue (eg, tunica media of aorta), and defects in its expression result in abnormal elastic fibers that lead to skeletal and cardiovascular anomalies in Marfan syndrome. ${ }^{13-16}$

The fibrillin-1 gene mutations in Marfan syndrome are normally clustered in the region of exons 24 to 28. Mutations in the fibrillin-2 gene have also been implicated in the pathogenesis of Marfan syndrome. ${ }^{13-16}$ The gene abnormalities include a wide range of point mutations, repeats, deletions, premature stop codons, and so forth. The genetic abnormalities in Marfan syndrome produce a wide range of results, ranging from virtually all the fibrillin being the mutant type to individuals with less than $10 \%$ mutant fibrillin, the rest being the wild type. This results in a huge phenotypic range of severity. ${ }^{13-16}$

We confined our search to exons 24 to 28 on the basis of the clustering of abnormalities in these exons in patients with Marfan syndrome. Characteristics of these patients with dilated aortic root and gene polymorphs compared with controls included older age at repair (>96 months), presence of MAPCAs, right aortic arch, degree of aortic override greater than $50 \%$, a higher prevalence of abnormal aortic histopathology (ie, elastic fragmentation), increased ground substance, medionecrosis, fibrosis, and an abnormally low lamellar count $(<55)$ (Table E3).

In this study, 5 patients with TOF showed a substitution change (c.3575C $<\mathrm{G})$ located in exon 27 , which led to a change in protein sequence (p.P1148A). This was reported earlier as mutation and later confirmed as polymorphism. Thus, the combination of exonic changes in the same patients on exons 27 and 28 and patients with polymorphism may have a causative role in aortic dilatation. This study did not demonstrate any point mutations, repeats, deletions, or premature stop codons in fibrillin-1 gene on exons 25 to 28 . However, it revealed a combination of exonic changes in the same patients on exons 27 and 28 and polymorphism in a subset of patients.

It is noteworthy that $96.4 \%$ of patients with elastic fragmentation $(P=.003), 78.6 \%$ of patients with increased ground substance $(P=.005), 67.8 \%$ of patients with medionecrosis $(P=.017), 53.6 \%$ of patients with muscle disarray $(P=.017)$, and $78.6 \%$ of patients with fibrosis $(P=.015)$ exhibited "exonic DNA sequence variations" involving the fibrillin-1 gene in 1 or more chromosomes (exons 27 and 28) (Table E3).

It is pertinent to state that in logistic regression analysis, the association between "exonic DNA sequence variants" and aortic dilatation showed a significant relationship with an OR of 10.92 (95\% CI, 2.31-51.49). The OR remained significant while adjusting for age $(6.87$ [95\% CI, 1.33$35.49 ; P=.02]$ ), and for age, increased ground substance, MAPCAs, and abnormal lamellar count $(9.85$ [95\% CI, 1.03-94.22; $P=.04]$ ).

The adjustment for differences in age, medionecrosis, MAPCAs, abnormal lamellar count, and for age, muscle disarray, MAPCAs, and abnormal lamellar count resulted in a moderate weakening of the OR to 6.49 (95\% CI, 0.9942.26; $P=.05)$ and 6.38 (95\% CI, 0.98-41.50; $P=.05$ ), respectively.

The relationship between DNA sequence variation and aortic dilatation became even weaker when adjusted for age and abnormal histopathology: 4.59 (95\% CI, 0.77-27.53). The adjustment for age, elastic fragmentation, presence of MAPCAs, abnormal lamellar count, and for age, fibrosis, presence of MAPCAs, and abnormal lamellar count increased the OR to 3.93 (95\% CI, 0.53-28.97) and 4.96 (95\% CI, 0.58-42.93), respectively, although both were nonsignificant (Table E5).

\section{Study Limitations}

We recognize that our study has limitations. This study was designed on the assumption that the nature and frequency of mutations in Marfan syndrome in Indians are not different from that found in the Caucasian population. In the absence of data regarding mutation in Marfan syndrome and TOF 
in the Indian population, this assumption remains unvalidated.

We found significant heterogeneity of clinical characteristics, such as age, gender, and other variables, including aortic diameter, between patients with normal and dilated aortas, which may have affected the results.

Our study has not investigated genetic abnormalities on other exons or abnormalities, such as neural crest markers and 22q.11 deletion in TOF. Our study illustrates that the mutations in exons 24 to 28 (the region of clustering of mutations in Marfan syndrome) of fibrillin-1 gene are not common in TOF. Whether mutations in other exons are common in TOF and their relationship (if any) in causing aortic dilatation need to be explored. The frequency of chromosome 22 q11.2 deletion by fluorescence in situ hybridization, occurrence of fibrillin-2 gene mutations, and transcription factor NKX 2.5 mutations (if any) in TOF with or without aortic dilatation are being explored.

Although SSCP analysis is the most commonly used method for screening, it has the following drawbacks: 1) The sensitivity varies from $60 \%$ to $80 \%$, depending on the gene to be analyzed, primer pairs used, and quality of tissue examined; thus, the investigator may miss a significant number of base changes. 2) Small gene segments, ranging from 150 to approximately 300 base pairs in length, can be screened only with SSCP. Larger genes will require multiple sets of primers and PCR products to cover the entire gene. 3) The sequence context and actual base substitution can influence the sensitivity of the assay, making it difficult to thoroughly standardize the assay for the entire gene sequence. ${ }^{23}$

Although allele-specific oligonucleotide hybridization analysis is a quick and simple way to screen for polymorphisms and mutations in specific gene sequences, a disadvantage of this technique is excess time consumption on screening more than 1 or 2 bases. $^{23}$

Other intermediate screening platforms, such as denaturing high performance liquid chromatography, denaturing gradient gel electrophoresis, conformation sensitive gel electrophoresis, and heteroduplex analysis have the potential to offer increased sensitivity, ranging from $80 \%$ to $99 \%$ and allow for analysis of larger fragments. ${ }^{21,23}$

In addition, denaturing high performance liquid chromatography screening is costly and more useful for a pilot study. Conformation sensitive gel electrophoresis also has $80 \%$ to 90\% sensitivity but cannot differentiate between homozygous and heterozygous changes. Thus, in deciding on the appropriate post-PCR analytic techniques, both the advantages and drawbacks of each technique should be taken into consideration. $^{21,23}$

\section{Conclusions}

Our findings indicate that the majority of aortic media of the ascending aorta in cyanotic TOF exhibit a significant loss of lamellar units and preexisting intrinsic aortopathy. An in- creased incidence of "exonic DNA variants" involving the fibrillin-1 gene in 1 or more chromosomes (exons 27 and 28) were noted in cyanotic TOF with dilated aorta in the presence of abnormal histopathology. These genetic abnormalities may account for or coexist with the higher incidence of aortic dilatation observed in these patients. On the basis of these results, at a minimum, we recommend screening for the above-mentioned genes along with larger-scale histopathologic studies of the aorta commencing in infancy.

\section{References}

1. Niwa K, Siu SC, Webb G, Gatzoulis M. Progressive aortic root dilatation in adults late after repair of tetralogy of Fallot. Circulation. 2002;106: 1374-8.

2. Dodds GA III, Warnes CA, Danielson GK. Aortic valve replacement after repair of pulmonary atresia and ventricular septal defect or tetralogy of Fallot. J Thorac Cardiovasc Surg. 1997;113:736-41.

3. Ricker RP, Berman MA, Stansel HC Jr. Postoperative studies in patients with tetralogy of Fallot. Ann Thorac Surg. 1975;19:17-25.

4. Warnes CA, Child JS. Aortic root dilatation after repair of tetralogy of Fallot: pathology from the past. Circulation. 2002;106:1310-1.

5. Tan LJ, Davlouros AP, McCarthy PK, Gatzoulis AM, et al. Intrinsic histological abnormalities of aortic root and ascending aorta in tetralogy of Fallot. Evidence of causative mechanism for aortic dilatation and aortopathy. Circulation. 2005;112:961-8.

6. Niwa K, Perloff JK, Bhuta SM, et al. Light and electron microscopy of dilated great arteries in congenital heart disease. J Am Coll Cardiol. 1997;29:1065-73.

7. Niwa K, Perloff JK, Bhuta SM, et al. Structural abnormalities of great arterial walls in congenital heart disease light and electron microscopic analyses. Circulation. 2001;103:393-400.

8. Niwa K. Aortic root dilatation in tetralogy of Fallot long-term after repair-histology of the aorta in tetralogy of Fallot: evidence of intrinsic aortopathy. Int J Cardiol. 2005;103:117-9.

9. Zecchel R, Ho SY, Davlouros PA, et al. Histology of the aorta, and aortic root dilatation in adults with tetralogy of Fallot. J Am Coll Cardiol. 2001; 37:468A.

10. Chowdhury UK, Mishra AK, Ray R, Kalaivani M, Reddy SM, Venugopal P. Histopathological changes in ascending aorta and the risk factors related to histopathological conditions and aortic dilatation in patients with tetralogy of Fallot. J Thorac Cardiovasc Surg. 2008; 135:69-77.

11. de Sa M, Moshkovitz Y, Butany J, David TE. Histologic abnormalities of the ascending aorta and pulmonary trunk in patients with bicuspid aortic value disease: clinical relevance to the Ross procedure. $J$ Thorac Cardiovasc Surg. 1999;118:588-96.

12. Perejola AJ, Abraham PA, Carnes W, Uilto J. Marfan syndrome: structural, biochemical and mechanical studies of the aortic media. J Lab Clin Med. 1985; 106:376-83.

13. Francke U, Furthmayur H. Marfan's syndrome and other disorders of fibrillin. N Engl J Med. 1994;330:1384-5.

14. Dietz H, Pyeritz R. Mutations in the human gene for fibrillin-1 Marfan syndrome and related disorders. Hum Med Genet. 1995;1799-809.

15. Watanabe Y, Yano S, Koga Y, et al. P1148A in fibrillin-1 is not a mutation leading to Shprintzen-Goldberg syndrome. Hum Mutat. 1997;10:326-7.

16. Schrijver I, Liu W, Francke U. The pathogenicity of the Pro1148Ala substitution in the FBN1 gene: causing or predisposing to Marfan syndrome and aortic aneurysm, or clinically innocent? Hum Genet. 1997; 99:607-11.

17. Amati F, Mari A, Digilio MC, et al. 22q11 deletions in isolated and syndromic patients with tetralogy of Fallot. Hum Genet. 1995;95:479-82.

18. Larson RS, Butler MG. Use of fluorescence in situ hybridization (FISH) in the diagnosis of DiGeorge sequence and related diseases. Diagn Mol Pathol. 1995;4:274-8.

19. Chugh R, Child JS, Perloff JK, et al. Echocardiographic characterization of the aortic root in adults with tetralogy of Fallot. Circulation. 2001; 104: II-558. Abstract. 
20. Schlatmann TJ, Becker AE. Histologic changes in the normal aging aorta: implications for dissecting aortic aneurysm. Am J Cardiol. 1977;39:13-20.

21. Körkkö J, Kaitila I, Lönnqvist L, Peltonen L, Ala-Kokko L. Sensitivity of conformation sensitive gel electrophoresis in detecting mutations in Marfan syndrome and related conditions. J Med Genet. 2002;39:34-41.

22. Sambrook J, Fritsch EF, Maniatis T. Molecular Cloning. A Laboratory Manual. Cold Spring Harbor, NY: Cold Spring Harbor Laboratory; 1989.

23. Mattes WB, Miller MS. In: Genetic Polymorphisms and Susceptibility to Disease. Chapter PCR: Method and limitations. Edited by Miller MS and Cronin MT. 1st ed. New York: Taylor and Francis Inc; 2000:17-39.

24. Vasan RS, Larson MR, Levy D. Determinations of echocardiography aortic root size: the Framingham heart Study. Circulation. 1995;89: 734-40.
25. Roman MJ, Devereux RB, Kramer-Fox R, et al. Two-dimensional echocardiographic aortic root dimensions in normal children and adults. Am J Cardiol. 1989;64:507-12.

26. Buja LM, Eigenbrodt ML, Eigenbrodt EH. Apoptosis and necrosis: basic types and mechanisms of cell death. Arch Pathol Lab Med. 1993;117: 1208-14.

27. Kim WH, Seo JW, Kim SJ, et al. Aortic dissection late after repair of tetralogy of Fallot. Int J Cardiol. 2005;101:515-6.

28. Rathi VK, Doyle M, Williams RB, et al. Massive aortic aneurysm and dissection in repaired tetralogy of Fallot; diagnosis by cardiovascular magnetic resonance imaging. Int J Cardiol. 2005;101:169-70.

29. Kirby ML, Gale TF, Stewart DE, et al. Neural crest cells contribute to normal aorticopulmonary septation. Science. 1983;220:1059-61.

30. Rosenquist TH, Beall AC, Modis L, et al. Impaired elastic matrix development in the great arteries after ablation of the cardiac neural crest. Anat Rec. 1990;226:347-59. 
TABLE E1. Demographic, operative, and postoperative details of the study group

\begin{tabular}{|c|c|}
\hline Patient-related variables & Mean \pm SD (range) \\
\hline Age at operation (mo) & $\begin{array}{c}112.6 \pm 104.52 \text { ( } 6 \text { mo to } 45 \mathrm{y} ; \\
\text { median, } 80 \mathrm{mo})\end{array}$ \\
\hline Age $<96$ mo & 41 \\
\hline$>96 \mathrm{mo}$ & 33 \\
\hline Male : Female & $52: 22$ \\
\hline Weight at operation $(\mathrm{kg})$ & $\begin{array}{c}25.50 \pm 12.80(2.5-72 \\
\text { median, } 17 \mathrm{~kg})\end{array}$ \\
\hline Body surface area $\left(\mathrm{m}^{2}\right)$ & $\begin{array}{c}0.92 \pm 0.28(0.19-1.8 \\
\left.\text { median } 0.82 \mathrm{~m}^{2}\right)\end{array}$ \\
\hline Previous Blalock-Taussig shunt & 25 \\
\hline Preoperative hemoglobin (g/dL) & $15.2 \pm 5.8(14-25)$ \\
\hline \multicolumn{2}{|l|}{ Preoperative hematocrit value } \\
\hline$<45 \%$ & 26 \\
\hline$>45 \%$ & 48 \\
\hline \multicolumn{2}{|l|}{$\begin{array}{c}\text { Preoperative right ventricular } \\
\text { end-diastolic pressure }\end{array}$} \\
\hline$<12 \mathrm{~mm} \mathrm{Hg}$ & 57 \\
\hline$>12 \mathrm{~mm} \mathrm{Hg}$ & 17 \\
\hline \multicolumn{2}{|l|}{$\begin{array}{l}\text { Preoperative systemic arterial } \\
\text { oxygen saturation }(\%)\end{array}$} \\
\hline$<80 \%$ & 43 \\
\hline$>80 \%$ & 31 \\
\hline Coil embolization of MAPCAs & 33 \\
\hline Right aortic arch & 21 \\
\hline \multicolumn{2}{|l|}{ Aortic override } \\
\hline$>50 \%$ & 42 \\
\hline$<50 \%$ & 32 \\
\hline \multicolumn{2}{|l|}{ Indexed aortic diameter } \\
\hline$>24.80 \mathrm{~mm} / \mathrm{m}^{2}$ & 51 \\
\hline$<24.80 \mathrm{~mm} / \mathrm{m}^{2}$ & 23 \\
\hline Indexed aortic diameter & $\begin{array}{c}25.80 \pm 10.50 \text { (range } 0-70 \\
\text { median } 24.80)\end{array}$ \\
\hline \multicolumn{2}{|l|}{ Aortic regurgitation } \\
\hline Yes & 13 \\
\hline No & 61 \\
\hline \multicolumn{2}{|l|}{ Diagnosis } \\
\hline TOF with pulmonary stenosis & 39 \\
\hline $\begin{array}{l}\text { DORV (Fallot type) and TOF } \\
\text { with pulmonary atresia }\end{array}$ & 35 \\
\hline Trans right-atrial approach & 16 \\
\hline $\begin{array}{l}\text { Trans right-atrial-pulmonary } \\
\text { artery approach }\end{array}$ & 58 \\
\hline Intact pulmonary annulus & 20 \\
\hline Limited transannular patch & 51 \\
\hline RV-to-PA homograft conduit & 3 \\
\hline $\begin{array}{l}\text { Lowest temperature at } \\
\text { operation }\end{array}$ & $28^{\circ} \mathrm{C}$ \\
\hline Aortic crossclamp time (min) & $40.0 \pm 12.0$ \\
\hline Hospital death & $3(4 \%)$ \\
\hline Late death & Nil \\
\hline $\begin{array}{c}\text { Preoperative peak systolic } \\
\text { pressure ratio (PRV/LV) }\end{array}$ & $0.98 \pm 0.06$ \\
\hline
\end{tabular}

TABLE E1. Continued

\begin{tabular}{lc}
\hline Patient-related variables & Mean \pm SD (range) \\
\hline $\begin{array}{c}\text { Postoperative peak systolic } \\
\text { pressure ratio (PRV/LV) } \\
\text { Postoperative mean } \\
\text { pulmonary artery pressure }\end{array}$ & $0.45 \pm 0.12$ \\
(mm Hg) & $14.8 \pm 4.2$ \\
\hline $\begin{array}{l}\text { MAPCA, Major aortopulmonary collateral artery; } S D, \text { standard deviation; } \\
\text { TOF, tetralogy of Fallot; } D O R V, \text { double outlet right ventricle; } L V \text {, left ventricle; } \\
P A, \text { pulmonary artery; } R V \text {, right ventricle. }\end{array}$
\end{tabular}


TABLE E2. Odds ratio for potential risk factors for aortic dilatation in patients undergoing intracardiac repair of tetralogy of Fallot (bivariate analysis) $(n=74)$

\begin{tabular}{|c|c|c|c|c|c|}
\hline \multirow[b]{2}{*}{ S. No. } & \multirow[b]{2}{*}{ Variables } & \multicolumn{3}{|c|}{ Aortic dilatation $(n=51)$} & \multirow[b]{2}{*}{$P$ value } \\
\hline & & No. & No. & OR ratio $(95 \% \mathrm{Cl})$ & \\
\hline \multirow[t]{3}{*}{1.} & Aortic wall histology & & & & \\
\hline & - Abnormal & 58 & 49 & $38.11(7.37-197.11)$ & $<.001$ \\
\hline & - Normal control & 16 & 2 & & \\
\hline \multirow{3}{*}{2.} & Elastic fragmentation & & & & \\
\hline & - Present & 58 & 49 & $38.11(7.37-197.11)$ & $<.001$ \\
\hline & - Absent & 16 & 14 & & \\
\hline \multirow[t]{3}{*}{3.} & Increased ground substance & & & & \\
\hline & - Present & 43 & 40 & $24.24(6.07-96.83)$ & $<0.001$ \\
\hline & - Absent & 31 & 11 & & \\
\hline \multirow[t]{3}{*}{4.} & Medionecrosis & & & & \\
\hline & - Present & 37 & 31 & $4.39(1.48-13.03)$ & .006 \\
\hline & - Absent & 37 & 20 & & \\
\hline \multirow[t]{3}{*}{5.} & Muscle disarray & & & & \\
\hline & - Present & 27 & 23 & $3.90(1.16-13.09)$ & .02 \\
\hline & - Absent & 47 & 28 & & \\
\hline \multirow[t]{3}{*}{6.} & Fibrosis & & & & \\
\hline & - Present & 45 & 40 & $13.09(3.96-43.23)$ & $<.001$ \\
\hline & - Absent & 29 & 11 & & \\
\hline \multirow[t]{3}{*}{7.} & Age & & & & \\
\hline & - $>96 \mathrm{mo}$ & 33 & 31 & $16.27(3.43-77.10)$ & $<.001$ \\
\hline & - $<96 \mathrm{mo}$ & 41 & 20 & & \\
\hline \multirow[t]{3}{*}{8.} & Sex & & & & \\
\hline & - Male & 52 & 44 & $11.78(3.65-38.03)$ & $<0.001$ \\
\hline & - Female & 22 & 7 & & \\
\hline \multirow[t]{3}{*}{9.} & Systemic arterial oxygen saturation & & & & \\
\hline & $<80 \%$ & 43 & 37 & $7.48(2.45-22.85)$ & $<.001$ \\
\hline & - $>80 \%$ & 31 & 14 & & \\
\hline \multirow[t]{3}{*}{10.} & Hematocrit & & & & \\
\hline & - $>45 \%$ & 48 & 37 & $2.88(1.03-8.03)$ & .04 \\
\hline & - $<45 \%$ & 26 & 14 & & \\
\hline \multirow[t]{3}{*}{11.} & Aortic override & & & & \\
\hline & - $>50 \%$ & 42 & 40 & $38.18(7.73-188.46)$ & $<.001$ \\
\hline & - $<50 \%$ & 32 & 11 & & \\
\hline \multirow[t]{3}{*}{12.} & Aortic regurgitation & & & & \\
\hline & - Yes & 13 & 12 & $6.77(0.82-55.60)$ & .04 \\
\hline & - No & 61 & 39 & & \\
\hline \multirow[t]{3}{*}{13.} & MAPCAs & & & & \\
\hline & - Present & 33 & 27 & $5.34(1.59-17.93)$ & .004 \\
\hline & - Absent & 43 & 24 & & \\
\hline \multirow[t]{3}{*}{14.} & Previous palliation & & & & \\
\hline & - Yes & 25 & 20 & $2.32(0.74-7.25)$ & .11 \\
\hline & - No & 49 & 31 & & \\
\hline \multirow[t]{3}{*}{15.} & Right ventricular end-diastolic pressure & & & & \\
\hline & - $>12 \mathrm{~mm} \mathrm{Hg}$ & 17 & 16 & $10.06(1.24-81.27)$ & .008 \\
\hline & - $<12 \mathrm{~mm} \mathrm{Hg}$ & 57 & 35 & & \\
\hline \multirow[t]{3}{*}{16.} & Right aortic arch & & & & \\
\hline & - Yes & 21 & 19 & $6.23(1.31-29.59)$ & .009 \\
\hline & - No & 53 & 32 & & \\
\hline 17. & Diagnosis & & & & \\
\hline & - TOF with PS & 39 & 20 & $0.13(0.04-0.46)$ & $<.001$ \\
\hline & - DORV, TOF with PA & 35 & 31 & & \\
\hline
\end{tabular}


TABLE E2. Continued

\begin{tabular}{|c|c|c|c|c|c|}
\hline \multirow[b]{2}{*}{ S. No. } & \multirow[b]{2}{*}{ Variables } & \multicolumn{3}{|c|}{ Aortic dilatation $(n=51)$} & \multirow[b]{2}{*}{$P$ value } \\
\hline & & No. & No. & $\mathrm{OR}$ ratio $(95 \% \mathrm{Cl})$ & \\
\hline \multirow[t]{3}{*}{18.} & Lamellar count & & & & \\
\hline & - Abnormal (mean \pm SD $37.3 \pm 8.7$; range $15-51)$ & 46 & 40 & $6.75(1.65-27.58)$ & .008 \\
\hline & - $\quad$ Normal (mean \pm SD $63.5 \pm 6.3$; range $55-75)$ & 28 & 11 & & \\
\hline \multirow[t]{3}{*}{19.} & Fibrillin-1 exonic DNA variants & & & & \\
\hline & - Yes & 28 & 26 & $10.92(2.31-51.49)$ & .003 \\
\hline & - No & 46 & 25 & & \\
\hline
\end{tabular}

OR, Odds ratio; $C l$, confidence interval; MAPCA, major aortopulmonary collateral artery; TOF, tetralogy of Fallot; $P S$, pulmonary stenosis; DORV, double outlet right ventricle; $P A$, pulmonary artery; $S D$, standard deviation.

The authors are grateful to Mr. Shanker Sharma for preparation of the manuscript. 
TABLE E3. Relationship between patients with and without "DNA sequence variants" with other risk factors for aortic dilatation in the study population $(n=74)$

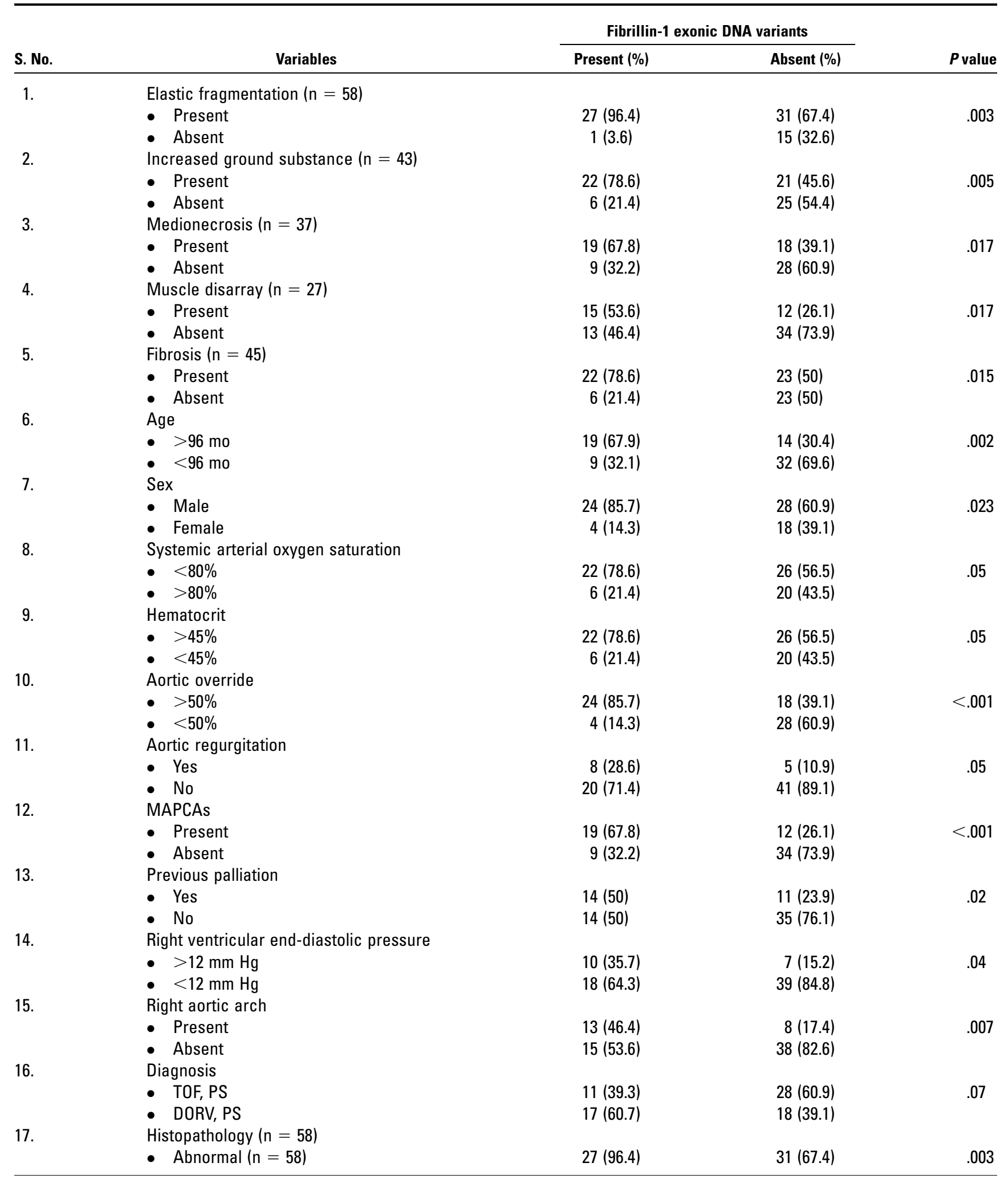


TABLE E3. Continued

Fibrillin-1 exonic DNA variants

\begin{tabular}{|c|c|c|c|c|}
\hline S. No. & Variables & Present (\%) & Absent (\%) & $P$ value \\
\hline \multirow[t]{3}{*}{18.} & $\begin{array}{l}\text { - Normal }(n=16) \\
\text { Lamellar count }\end{array}$ & $1(3.6)$ & $15(32.6)$ & \\
\hline & - $<55$ & $21(75)$ & $25(54.4)$ & .007 \\
\hline & - $>55$ & $7(25)$ & $21(45.6)$ & \\
\hline
\end{tabular}

TOF, Tetralogy of Fallot; $P S$, pulmonary stenosis; DORV, double outlet right ventricle. 
TABLE E4. Predictors of aortic dilatation by stepwise logistic regression analysis applied to all 74 patients

\begin{tabular}{lrr}
\hline \multicolumn{1}{c}{ Variables (covariates adjusted) } & OR (95\% CI) & $\boldsymbol{P}$ value \\
\hline 1. Histopathologically abnormal aorta & $8.83(1.94-39.99)$ & .005 \\
2. Elastic fragmentation & $8.83(1.94-39.99)$ & .005 \\
3. Increased ground substance $(\mathrm{n}=53)$ & $9.65(1.97-47.34)$ & .005 \\
4. Male sex & $26.11(4.03-169.20)$ & .001 \\
5. DORV & $7.61(1.26-46.12)$ & .003 \\
6. Aortic override $>50 \%$ & $6.75(1.65-27.58)$ & .008 \\
7. Fibrillin-1 exonic DNA variants & $8.11(1.93-34.04)$ & .004 \\
\hline
\end{tabular}

$O R$, Odds ratio; $\mathrm{Cl}$, confidence interval; DORV, double outlet right ventricle. 
TABLE E5. Logistic regression analyses of the association between patients with fibrillin-1 "exonic DNA sequence variants" and aortic dilatation in the study population

\begin{tabular}{|c|c|c|c|}
\hline & $\begin{array}{l}\text { DNA sequence variants } \\
\quad \text { (absent, } n=46)\end{array}$ & $\begin{array}{l}\text { DNA sequence variants } \\
\quad \text { (present, } n=28 \text { ) }\end{array}$ & \\
\hline & $\begin{array}{c}\text { Normal aorta }(n=23) \text { DNA } \\
\text { sequence variants }(+)(n=2)\end{array}$ & $\begin{array}{c}\text { Dilated aorta }(n=51) \text { DNA } \\
\text { sequence variants }(+)(n=26)\end{array}$ & \\
\hline & $\mathbf{O R}$ & OR $(95 \% \mathrm{Cl})$ & $P$ value \\
\hline Unadjusted & 1.0 & $10.92(2.31-54.49)$ & .003 \\
\hline Adjusted for & & & \\
\hline Age & 1.0 & $6.87(1.33-35.49)$ & .02 \\
\hline Age and abnormal histopathology & 1.0 & $4.59(0.77-27.53)$ & .09 \\
\hline $\begin{array}{l}\text { Age, presence of elastic fragmentation, MAPCAs, } \\
\text { and abnormal lamellar count }\end{array}$ & 1.0 & $3.93(0.53-28.97)$ & .18 \\
\hline $\begin{array}{l}\text { Age, presence of increased ground substance, } \\
\text { MAPCAs, and abnormal lamellar count }\end{array}$ & 1.0 & $9.85(1.03-94.22)$ & .04 \\
\hline $\begin{array}{l}\text { Age, presence of medionecrosis, MAPCAs, and } \\
\text { abnormal lamellar count }\end{array}$ & 1.0 & $6.49(0.99-42.26)$ & .05 \\
\hline $\begin{array}{l}\text { Age, presence of muscle disarray, MAPCAs, and } \\
\text { abnormal lamellar count }\end{array}$ & 1.0 & $6.38(0.98-41.50)$ & .05 \\
\hline $\begin{array}{l}\text { Age, presence of fibrosis, MAPCAs, and } \\
\text { abnormal lamellar count }\end{array}$ & 1.0 & $4.96(0.58-42.23)$ & .14 \\
\hline
\end{tabular}

$O R$, Odds ratio; $\mathrm{Cl}$, confidence interval; $M A P C A$, major aortopulmonary collateral artery. 
TABLE E6. Histologic definitions and grading of tunica media sections of the aortic wall

\begin{tabular}{|c|c|c|c|}
\hline Histology & Grade 1 & Grade 2 & Grade 3 \\
\hline \multicolumn{4}{|l|}{ Medionecrosis } \\
\hline $\begin{array}{l}\text { Focal loss of smooth } \\
\text { muscle cell nuclei media }\end{array}$ & $\begin{array}{l}\text { Focal loss consisting of }<1 / 3 \\
\text { of total width of media }\end{array}$ & $\begin{array}{l}\text { Focal loss consisting of } 1 / 3 \\
\text { to } 2 / 3 \text { of media thickness }\end{array}$ & $\begin{array}{l}\text { Focal loss consisting of }>2 / 3 \text { of } \\
\text { media thickness }\end{array}$ \\
\hline \multicolumn{4}{|l|}{ Fibrosis } \\
\hline $\begin{array}{l}\text { Increases in interstitial } \\
\text { collagen }\end{array}$ & $\begin{array}{l}\text { Fibrosis in }<1 / 3 \text { of total width } \\
\text { of media or focal accumulation } \\
\text { throughout }\end{array}$ & $\begin{array}{l}\text { Fibrosis in } 1 / 3 \text { to } 2 / 3 \text { of total } \\
\text { width of media with multiple } \\
\text { small areas of fibrosis }\end{array}$ & $\begin{array}{l}\text { Fibrosis in }>2 / 3 \text { of total width of } \\
\text { media with multiple small } \\
\text { areas of fibrosis }\end{array}$ \\
\hline \multicolumn{4}{|c|}{ Cystic medial necrosis (mucoid accumulation) } \\
\hline $\begin{array}{l}\text { Cysts are observed in } \\
\text { presence of intact elastic } \\
\text { lamellae and fragmented } \\
\text { elastic fibers }\end{array}$ & $\begin{array}{l}\text { Minute foci within a single lamellar } \\
\text { unit not encompassing its } \\
\text { entire width }\end{array}$ & $\begin{array}{l}\text { Increased size and No. of } \\
\text { "cysts" plus mucoid material } \\
\text { covering the total width of } 1 \\
\text { lamellar unit }\end{array}$ & $\begin{array}{l}\text { Large and extended "cysts" } \\
\text { (>1 lamellar unit) with } \\
\text { fragmentation of elastic } \\
\text { fibers }\end{array}$ \\
\hline \multicolumn{4}{|l|}{ Elastic fragmentation } \\
\hline $\begin{array}{l}\text { Focal fragmentation of } \\
\text { elastic lamellae in aortic } \\
\text { media }\end{array}$ & $\begin{array}{l}<5 \text { foci of elastic lamellae } \\
\text { fragmentation in } 1 \text { microscopic } \\
\text { field of } \times 200\end{array}$ & $\begin{array}{l}5 \text { to } 9 \text { foci of elastic lamellae } \\
\text { fragmentation in } 1 \\
\text { microscopic field of } \times 200\end{array}$ & $\begin{array}{l}\geq 10 \text { foci of elastic lamellae } \\
\quad \text { fragmentation in } 1 \\
\quad \text { microscopic field of } \times 200\end{array}$ \\
\hline Elastic lamellae & $\begin{array}{l}\text { Total No. of elastic lamellae in media were } \\
\text { counted. Median value in different age } \\
\text { groups was used as the "cutoff" value } \\
\text { to differentiate normal from abnormal }\end{array}$ & & \\
\hline
\end{tabular}


TABLE E7. Sets of primers used for polymerase chain reaction amplification for all 5 exons (24-28)

\begin{tabular}{|c|c|c|c|c|}
\hline Set & Exons & Primers & $\begin{array}{l}\text { Size of the } \\
\text { product }\end{array}$ & $\begin{array}{c}\text { Annealing } \\
\text { temperature }\end{array}$ \\
\hline I & 24 & $\begin{array}{l}\text { Forward 5'-CAGCAAATTATTATGTGTGCAG } \\
\text { Reverse 5'- ATCAAGTAGAGTGCTGAGATC }\end{array}$ & 418 & 60 \\
\hline II & 25 & $\begin{array}{l}\text { Forward 5'-CAAGAACTTCCAACCTTCATG } \\
\text { Reverse 5'-ACAGCCTTAATTCTTGCGACA }\end{array}$ & 313 & 60 \\
\hline III & 26 & $\begin{array}{l}\text { Forward 5'-CTTAAGGGCCAGGAGAGGG } \\
\text { Reverse 5'-ACCTGGAACATAGGCTATGAG }\end{array}$ & 321 & 60 \\
\hline IV & 27 & $\begin{array}{l}\text { Forward 5'-GGAGGAGTGCTTGGTCTGG } \\
\text { Reverse 5'-CAAACATAAGCTTCCAACTTTGGC }\end{array}$ & 276 & 60 \\
\hline V & 28 & $\begin{array}{l}\text { Forward 5'-CGTGTATCGGTAAGGAGAAAGAC } \\
\text { Reverse 5'-ACAAAACTCAGAGTACATAGAG }\end{array}$ & 373 & 55 \\
\hline
\end{tabular}


TABLE E8. Single-strand conformation polymorphism analysis of the amplified products to identify sequence alterations

\begin{tabular}{lcc}
\hline Sequence alteration & Amino acid alteration & Exon \\
\hline 3037 G to A & G 101 3R & 24 \\
3069 G to C & K 1023 N & 24 \\
3174 INS 3 & 1058 ins C & 25 \\
3217 G to A & E 1073 K & 26 \\
3220 T to C & C 1073 K & 26 \\
3350 G to A & C 1074 R & 27 \\
3410 G to C & C 1117 Y & 27 \\
3464 del 17 & Frameshift & 28 \\
\hline
\end{tabular}

